\title{
AUTHOR INDEX FOR VOLUME 90
}

ABDOLLAHI, A. and GHORAISHI, S. M.; On noninner 2-automorphisms of finite 2-groups

ALI, Z. M.; see MAJID, R. N.

AYALA, J.; Connectedness and minimal length elements in spaces of bounded curvature paths

BAHLEKEH, A.; (Strongly) Gorenstein flat modules over group rings

BALLESTER-BOLINCHES, A., BEIDLEMAN, J. C., ESTEBAN-ROMERO, R. and RAGLAND, M. F.; On a class of supersoluble groups

BANARU, M. B.; Special Hermitian manifolds and the 1-cosymplectic hypersurfaces axiom

BEER, G. and GARRIDO, M. I.; Bornologies and locally Lipschitz functions

BEIDLEMAN, J. C.; see BALLESTER-BOLINCHES, A.

BÉKOLLÉ, D., ISHI, H. and NANA, C.; Korányi’s lemma for homogeneous Siegel domains of type II. Applications and extended results

BELL, J. P., COONS, M. and HARE, K. G.; The minimal growth of a $k$-regular sequence

BHATT, S. J., DABHI, P. A. and DEDANIA, H. V.; The multiplier algebra of a Beurling algebra

CASTILlo, C., COUlTER, R. S. and SMITH, S.; A note on interpolation of permutations of a subset of a finite field

CHANG, M.-C. and SHPARLINSKI, I. E.; Double character sums over subgroups and intervals

CHEN, J. X., CHEN, Z. L. and JI, G. X.; Domination by positive weak ${ }^{*}$ DunfordPettis operators on Banach lattices

CHEN, M. and GAO, P.; A new unique continuation property for the Kortewegde Vries equation

CHEN, Z. L.; see CHEN, J. X.

CHIODO, M.; Finitely annihilated groups

COONS, M.; see BELL, J. P.

COULTER, R. S.; see CASTILLO, C.

CURTIN, B. and POURGHOLI, G. R.; A group sum inequality and its application to power graphs

DABHI, P. A.; see BHATT, S. J.

DEDANIA, H. V.; see BHATT, S. J.

DONG, X.-T., LIU, C. and ZHOU, Z.-H.; Quasihomogeneous Toeplitz operators with integrable symbols on the harmonic Bergman space

DONSIG, A. P. and MILAN, D.; Joins and covers in inverse semigroups and tight $C^{*}$-algebras

DOUBTSOV, E.; Characterisations of Hardy growth spaces with doubling weights 
DRAGOMIR, S. S.; see HWANG, D.-Y.

DRAGOMIR, S. S.; Some inequalities of Jensen type for Arg-square convex functions of unitary operators in Hilbert spaces

ESTEBAN-ROMERO, R.; see BALLESTER-BOLINCHES, A.

FENG, M.; see TANG, M.

FISHMAN, L., LY, T. and SIMMONS, D.; Determinacy and indeterminacy of games played on complete metric spaces

FLAMMANG, V.; The total distance for totally positive algebraic integers

FOULADI, S. and ORFI, R.; Noninner automorphisms of order $p$ in finite $p$-groups of coclass 2 , when $p>2$

GAO, P.; Carleman estimate and unique continuation property for the linear stochastic Korteweg-de Vries equation

GARRIDO, M. I.; see BEER, G.

GE, S., WANG, W. and YANG, Q.; Dependence of eigenvalues of sixth-order boundary value problems on the boundary

GHORAISHI, S. M.; see ABDOLLAHI, A.

HARE, K. G.; see BELL, J. P.

HE, W.; see WANG, H.

HU, P.-C. and YANG, C.-C.; The Tumura-Clunie theorem in several complex variables

HWANG, D.-Y. and DRAGOMIR, S. S.; Some results on comparing two integral means for absolutely continuous functions and applications

INOAN, D.; An existence result for a variational-like inequality

ISHI, H.; see BÉKOLLÉ, D.

IZADI, F., KHOSHNAM, F., MOODY, D. and ZARGAR, A. S.; Elliptic curves arising from Brahmagupta quadrilaterals

JI, G. X.; see CHEN, J. X.

JIANG, Q. and SHAO, C.; Solvability of finite groups with four conjugacy class sizes of certain elements

KACHOUR, C.; Aspects of globular higher category theory

KĄKOL, J., SAXON, S. A. and TODD, A. R.; Barrelled spaces with(out) separable quotients

KHOSHNAM, F.; see IZADI, F.

LEŚNIAK, K.; On discrete stochastic processes with disjunctive outcomes

LI, H.-X.; see ZHANG, L.-L.

LI, X.-M. and YI, H.-X.; Remarks on value sharing of certain differential polynomials of meromorphic functions

LIN, B. L. S. and WANG, A. Y. Z.; Generalisation of Keith's conjecture on 9-regular partitions and 3-cores

LING, B., WU, C. X. and LOU, B. G.; Pentavalent symmetric graphs of order 30p 
LONGSTAFF, W. E.; Reflexive index of a family of subspaces 134

LOU, B. G.; see LING, B.

LY, T.; see FISHMAN, L. $\quad 339$

MA, S.-M.; On $\gamma$-vectors and the derivatives of the tangent and secant functions 177

MAGHSOUDI, S. and SEOANE-SEPÚLVEDA, J. B.; Hypergroup algebras as topological algebras

486

MAJID, R. N., SUNDARARAJAN, E. and ALI, Z. M.; An efficient method for improving the computational performance of the cubic Lucas cryptosystem

MARKOWSKY, G.; A probabilistic proof of the Open Mapping theorem for analytic functions

MILAN, D.; see DONSIG, A. P.

MIYAZAKI, T. and TERAI, N.; On the exponential Diophantine equation $\left(m^{2}+1\right)^{x}+\left(\mathrm{cm}^{2}-1\right)^{y}=(\mathrm{am})^{z}$

MOODY, D.; see IZADI, F.

NANA, C.; see BÉKOLLÉ, D.

ORFI, R.; see FOULADI, S.

PARK, K.-S.; Warped products in Riemannian manifolds

PETROVIĆ, LJ. and VALJAREVIĆ, D.; Statistical causality and martingale representation property with application to stochastic differential equations

POURGHOLI, G. R.; see CURTIN, B.

327

RAGLAND, M. F.; see BALLESTER-BOLINCHES, A.

RUSSO, F. G.; On a problem of P. Hall for Engel words II 237

SAXON, S. A.; see KĄKOL, J.

295

SEOANE-SEPÚLVEDA, J. B.; see MAGHSOUDI, S. 486

SHAO, C.; see JIANG, Q.

SHI, W.-X.; see XUAN, W.-F.

SHI, W.-X.; see XUAN, W.-F.

SHPARLINSKI, I. E.; see CHANG, M.-C. 376

SIMMONS, D.; see FISHMAN, L. $\quad 339$

SMITH, S.; see CASTILLO, C.

SOLTANI, H. and ZAKER, M.; On dynamic monopolies of graphs with probabilistic thresholds

SUNDARARAJAN, E.; see MAJID, R. N.

TANAKA, R.; A further property of spherical isometries 304

TANG, M. and FENG, M.; On deficient-perfect numbers 186

TERAI, N.; A note on the Diophantine equation $x^{2}+q^{m}=c^{n} \quad 20$

TERAI, N.; see MIYAZAKI, T.

TODD, A. R.; see KĄKOL, J.

VALJAREVIĆ, D.; see PETROVIĆ, LJ. 327

WANG, A. Y. Z.; see LIN, B. L. S. 204

WANG, H. and HE, W.; A note on $K$-spaces 144

WANG, W.; see GE, S. $\quad 457$ 
WANG, Y; The quantitative distribution of Hecke eigenvalues

WATSON, N. A.; Regularity of boundary points in the Dirichlet problem for the heat equation

XUAN, W.-F. and SHI, W.-X.; A note on spaces with a rank 3-diagonal 521

XUAN, W.-F. and SHI, W.-X.; A note on spaces with rank 2-diagonal 141

YANG, C.-C.; see HU, P.-C. 444

YANG, Q.; see GE, S.

YAO, O. X. M.; New infinite families of congruences modulo 4 and 8 for 1 -shell totally symmetric plane partitions

YI, H.-X.; see LI, X.-M.

ZAKER, M.; see SOLTANI, H. 363

ZARGAR, A. S.; see IZADI, F.

ZARRIN, M.; On solubility of groups with few normalisers 247

ZELENYUK, Y. and ZELENYUK, Y.; Counting symmetric colourings of the vertices of a regular polygon

ZELENYUK, Y.; see ZELENYUK, Y.

ZHANG, L.-L. and LI, H.-X.; Almost automorphic solutions for differential equations with piecewise constant argument

ZHANG, Y. and ZHU, G.; A positive solution for a nonlocal Schrödinger equation 


\section{INFORMATION FOR AUTHORS}

The Bulletin of the Australian Mathematical Society aims at quick publication of original research in all branches of mathematics. To ensure speedy publication, only articles which are sufficiently well presented, able to be published without revision, and which are judged by the Editor (often in consultation with an Associate Editor) to be competitive are refereed. This policy is in the interests of authors, as a quick rejection is better than a slow rejection. The Bulletin receives more than five times the material that can be published, therefore there are many commendable papers not accepted. Editorial decisions on acceptance or otherwise are taken quickly, normally within a month of receipt of the paper. Papers are accepted only after peer review.

Manuscripts are accepted for review with the understanding that the same work is not concurrently submitted elsewhere. For a paper to be acceptable for publication, not only should it contain new and interesting results, but also

(i) the exposition should be clear and attractive, and

(ii) the manuscript should be in publishable form, without revision.

Further information regarding these requirements may be found through our website www.austms.org.au/Bulletin. Authors are asked to avoid, as far as possible, the use of mathematical symbols in the title.

Articles should be prepared in LTEX using $\mathcal{A}_{\mathcal{M}} \mathcal{S}$-LTTEX packages and submitted as a PDF file via our journal management system, at www.austms.org.au/Publications/Submissions/BAustMS. This permits authors to track their papers through the editorial process. Recent versions of $\mathrm{T}_{\mathrm{E}} \mathrm{X}$ are able to produce PDF files directly. A LATEX class file for the Bulletin can be downloaded from the website. Authors who need assistance may email the secretary of the Bulletin at editor@ bulletin.austms.org.au.

Authors are advised to keep copies of all files of the submitted article; the Bulletin will not accept responsibility for any loss.

\section{EDITORIAL POLICY}

1. References. Arrange references alphabetically (by surname of the first author) and cite them numerically in the text. Ensure the accuracy of the references: authors' names should appear as in the work quoted. Include in the list of references only those works cited, and avoid citing works which are in preparation or submitted. Where the work cited is not readily accessible (for example, a preprint) a copy of the article should be included with your submission.

\section{Abstracts.}

1. Each paper must include an abstract of not more than 150 words, which should contain a brief but informative summary of the contents of the paper, but no inessential details.

2. The abstract should be self-contained, but may refer to the title.

3. Specific references (by number) to a section, proposition, equation or bibliographical item should be avoided.

3. Subject Classification and Key Words. Authors should include a few key words and phrases and one or more classification numbers, following the American Mathematical Society 2010 Mathematics Subject Classification for all codes. Details of this scheme can be found on the web at www.ams.org/msc.

4. Abstracts of PhD Theses. The Bulletin endeavours to publish abstracts of all accepted Australasian $\mathrm{PhD}$ theses in mathematics. One restriction, however, is that the abstract must be received by the Editor within six months of the degree being approved.

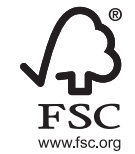

This journal issue has been printed on FSC-certified paper and cover board. FSC is an independent, non-governmental, not-for-profit organisation established to promote the responsible management of the world's forests. Please see www.fsc.org for information. 


\section{Table of Contents}

Pentavalent symmetric graphs of order $30 p$

Ling, B., Wu, C. X. \& Lou, B. G.

On dynamic monopolies of graphs with probabilistic thresholds

Soltani, H. \& Zaker, $M$.

Double character sums over subgroups and intervals

Chang, M.-C. E Shparlinski, I. E.

The total distance for totally positive algebraic integers

Flammang, $V$.

Finitely annihilated groups

Chiodo, $M$.

A group sum inequality and its application to power graphs

Curtin, B. \& Pourgholi, G. R.

Remarks on value sharing of certain differential polynomials of meromorphic functions

$L i, X .-M$. \& $Y i, H .-X$.

The Tumura-Clunie theorem in several complex variables

Hu, P.-C. \& Yang, C.-C.

Dependence of eigenvalues of sixth-order boundary value problems on the boundary

Ge, S., Wang, W. \& Yang, Q.

A positive solution for a nonlocal Schrödinger equation

Zhang, $Y$. \& Zhu, $G$.

Regularity of boundary points in the Dirichlet problem for the heat equation

Watson, $\mathcal{N} . A$.

Hypergroup algebras as topological algebras

Maghsoudi, S. E Seoane-Sepúlveda, 7. B.

Quasihomogeneous Toeplitz operators with integrable symbols on the harmonic Bergman space Dong, X.-T., Liu, C. \& Zhou, Z.-H.

Special Hermitian manifolds and the 1-cosymplectic hypersurfaces axiom

Banaru, $M$. B.

Warped products in Riemannian manifolds

Park, K.-S.

A note on spaces with a rank 3-diagonal

Xuan, W.-F. \& Shi, W.-X.

Author Index for Volume 90 